\title{
Heteroplasmic Mutations and Polymorphisms in the $C y b$ Gene of Mitochondrial DNA in Canine Mast Cell Tumours
}

\author{
ANNA ŚMIECH ${ }^{1}$, BRYGIDA ŚLASKA ${ }^{2}$, ADAM BOWNIK ${ }^{2}$, LUDMIŁA GRZYBOWSKA-SZATKOWSKA ${ }^{3}$, \\ JAROSŁAW DUDKA ${ }^{4}$ and WOJCIECH ŁOPUSZYŃSKI ${ }^{1}$ \\ ${ }^{1}$ Sub-Department of Pathomorphology and Forensic Veterinary Medicine, \\ Department and Clinic of Internal Animal Diseases, Faculty of Veterinary Medicine, \\ University of Life Sciences in Lublin, Lublin, Poland; \\ ${ }^{2}$ Department of Biological Bases of Animal Production, \\ Faculty of Animal Breeding and Biology, University of Life Sciences in Lublin, Lublin, Poland; \\ ${ }^{3}$ Department of Oncology, Medical University of Lublin, Lublin, Poland; \\ ${ }^{4}$ Chair and Department of Toxicology, Medical University of Lublin, Lublin, Poland
}

\begin{abstract}
Aim: Identification of mutations and polymorphisms in the cytochrome b gene (Cyb) of mitochondrial DNA (mtDNA) in canine mast cell tumours and determinatiion of their association with the process of neoplastic transformation. Materials and Methods: The samples comprised tumour tissues and blood obtained from 34 dogs of various breeds. Mutations and polymorphisms in the Cyb gene were detected using amplification and sequencing methods. Results: Heteroplasmic mutations were detected at seven positions of mtDNA in $86 \%$ of the individuals. Blood and tumour heteroplasmy were recorded at five nucleotide positions of the Cyb gene, whereas tumour heteroplasmy was detected at two positions. Polymorphisms were detected at 14 Cyb gene positions in in the blood of $91 \%$ of dogs with mast cell tumours. Conclusion: The presence of numerous mutations and polymorphisms of Cyb in the blood and tumour tissues and the high frequency of heteroplasmy indicate their involvement in the process of neoplastic transformation in dogs.
\end{abstract}

Mast cell tumours (MCTs) are the most frequent canine skin tumours as they account for $7-21 \%$ of all diagnosed neoplastic lesions of this organ (1). Boxers are at the greatest

This article is freely accessible online.

Correspondence to: Anna Śmiech, Sub-Department of Pathomorphology and Forensic Veterinary Medicine, Department and Clinic of Internal Animal Diseases, Faculty of Veterinary Medicine, University of Life Sciences in Lublin, Głęboka 30 St., 20-950 Lublin, Poland. E-mail: anna.smiech@up.lublin.pl

Key Words: Cyb gene, dog, mast cell tumours, mtDNA, mutations, mitochondrial DNA. risk of the disease, but Shar-Peis, Pugs, Labrador Retrievers, Golden Retrievers, Boston terriers and Pitt-Bull are also frequently mentioned in this context (2). However, in Boxers and Pugs, MCTs are commonly of histologically low or intermediate malignancy grade, whereas more aggressive course of MCTs has been observed in young Shar-Peis. The multifocal form of MCTs has been reported in Golden Retrievers $(1,2)$. MCTs can develop at any age, but the peak of their incidence is noted between 7.5 and 9 years of age (1). Most studies report no correlation between the sex of an animal and MCT occurrence as well as no gender predilection $(1,2)$. Due to their complex biological nature and unexplained aetiology, MCTs are still a subject of scientific research. The current knowledge about disturbances in the genetic material of MCTs is primarily focused on nuclear DNA (nDNA). The presence of internal tandem duplication (ITD) mutations in exon 11 of the proto-oncogene KIT protooncogene receptor tyrosine kinase ( $c$-Kit) has been shown in $30 \%$ of this type of tumour $(3,4)$. Compared with mutations in exon 11, ITD mutations in exons 8 and 9 of $c$-Kit have been identified less frequently (5\%) (5).

With the improvement of molecular biology techniques, involvement of the mitochondria in carcinogenesis is being increasingly suggested. Mitochondria possess their own genome characterised by higher variability than that of the nuclear genome. The frequency of mutations in mitochondrial DNA (mtDNA) is over 10-fold higher than their frequency in nDNA. Each cell contains from hundreds to thousands of mtDNA copies. When a cell/tissue contains both mutated and normal wild-type mtDNA, the condition is known as heteroplasmy. The presence of only one type of mtDNA (mutated or normal mtDNA) in the cell or tissue is homoplasmy. Mutations in mtDNA result in the synthesis of abnormal proteins of oxidative phosphorylation complexes, 
impaired cellular respiration, disorders in ATP production, and enhanced production of reactive oxygen species (6-8). Recent studies have documented the significant role of polymorphisms and mutations in mtDNA in the pathogenesis of many human diseases, including tumours (6-13). Somatic mtDNA mutations have also been detected in some canine tumours (14-18). Mutations and polymorphisms in genes coding for the respiratory chain subunits and in the displacement loop (D-loop) region have been found in mammary tumours as well as epithelial and mesenchymal tumours (16-18). Although there are relatively few literature data on the mitochondrial genomics of canine MCTs, mutations and polymorphisms have been detected in the Dloop region (19).

Mitochondrial diseases are associated with disorders in the function and biogenesis of respiratory chain components. Mutations in genes encoding respiratory chain subunit proteins induce changes in cell metabolism and may lead to neoplastic transformation $(7,8)$. Cytochrome $b$ (CYB) is a respiratory chain protein. It is an integral membrane protein and a component of the complex III subunit. The protein is involved in regulation of oxidoreductase activity, metal ion transfer, and electron transport in the respiratory chain (20). Mutations in the gene encoding cytochrome $b$ have been associated with some human tumour types, e.g. melanomas, mammary tumours, and bladder cancer $(12,21,22)$. To our knowledge, there are no literature reports on the occurrence and role of $C y b$ gene mutations in MCTs, which prompts undertaking such investigations.

The aim of this study was to identify mutations and polymorphisms in the $C y b$ gene of mtDNA in mast cell tumours in dogs and determine their association with the process of neoplastic transformation.

\section{Materials and Methods}

The study involved 34 dogs of different breeds and crossbreed dogs with diagnosed MCTs. The characteristics of the dogs are provided in Table I. The dogs received neither chemotherapy nor hormonotherapy. Tumour tissue and blood samples were collected during surgery from all dogs. Blood samples of $1 \mathrm{ml}$ each were taken from each dog using sterile test-tubes (Medlab Products, Raszyn, Poland) with di-potassium ethylene diaminetetra-acetic acid as an anticoagulant. All tumour tissues were sampled for histopathological and molecular analysis. Part of the tumour tissue for molecular analysis was transferred into sterile containers and kept in a refrigerator for further studies. For histopathology, part of the tissue was fixed in buffered formalin ( $\mathrm{pH}$ 7.2), processed routinely, embedded in paraffin wax, sectioned into $4-\mu \mathrm{m}$ fragments, stained with haematoxylin-eosin and toluidine blue, and evaluated under a light microscope for classification. Microscopic classification was performed in accordance with the WHO histological classification (23). The degree of histological malignancy was assessed using a 3grade scale (GI, GII, GIII) according to Patnaik et al. (24) considering the depth of infiltration, cellular and nuclear pleomorphism, presence of giant cells, appearance of cytoplasmic
Table I. Data on dogs with mast cell tumours included in the study.

\begin{tabular}{|c|c|c|c|c|}
\hline $\begin{array}{l}\text { Dog } \\
\text { number }\end{array}$ & Gender & Breed & $\begin{array}{l}\text { Age } \\
\text { (years) }\end{array}$ & $\begin{array}{l}\text { Grading according } \\
\text { to Patnaik et al. }(24) / \\
\text { Kiupel et al. }(25)\end{array}$ \\
\hline 1 & $\mathrm{~F}$ & Boxer & 8 & II/Low \\
\hline 2 & M & Golden Retriever & 7 & I/Low \\
\hline 3 & $\mathrm{~F}$ & Central Asian & 4 & II/High \\
\hline 4 & $\mathrm{~F}$ & Labrador Retriever & 35 & II/Low \\
\hline 5 & $\mathrm{~F}$ & Bernese Mountain Dog & 9 & III/High \\
\hline 6 & $\mathrm{~F}$ & Cane Corso & 8 & III/High \\
\hline 7 & $\mathrm{~F}$ & German Shepherd & 8 & II/Low \\
\hline 8 & M & Alaskan Malamute & 6 & I/Low \\
\hline 9 & $\mathrm{~F}$ & $\begin{array}{c}\text { German Shorthaired } \\
\text { Pointer }\end{array}$ & 10 & II/Low \\
\hline 10 & $\mathrm{~F}$ & Labrador Retriever & 5 & I/Low \\
\hline 11 & M & Labrador Retriever & 8 & III/High \\
\hline 12 & M & $\begin{array}{c}\text { American } \\
\text { Staffordshire Terrier }\end{array}$ & 8 & I/Low \\
\hline 13 & $\mathrm{~F}$ & Bull Terrier & 8 & I/Low \\
\hline 14 & $\mathrm{~F}$ & Crossbreed & 15 & II/Low \\
\hline 15 & $\mathrm{~F}$ & Golden Retriever & 12 & I/Low \\
\hline 16 & $\mathrm{~F}$ & Dachshund & 9 & III/High \\
\hline 17 & M & French Bulldog & 10 & I/Low \\
\hline 18 & $\mathrm{~F}$ & $\begin{array}{c}\text { American } \\
\text { Staffordshire Terrier }\end{array}$ & 8 & I/Low \\
\hline 19 & M & Ratter & 15 & III/High \\
\hline 20 & M & French Bulldog & 7 & III/High \\
\hline 21 & $\mathrm{~F}$ & Crossbreed & 12 & II/Low \\
\hline 22 & $\mathrm{~F}$ & Labrador Retriever & 6 & III/High \\
\hline 23 & $\mathrm{M}$ & Shar-Pei & 8 & III/High \\
\hline 24 & $\mathrm{~F}$ & $\begin{array}{c}\text { Bavarian Mountain } \\
\text { Hound }\end{array}$ & 9 & III/High \\
\hline 25 & $\mathrm{~F}$ & Golden Retriever & 4 & I/Low \\
\hline 26 & $\mathrm{~F}$ & Saint Bernard & 6 & II/High \\
\hline 27 & M & French Bulldog & 10 & II/Low \\
\hline 28 & $\mathrm{~F}$ & Crossbreed & 8 & II/Low \\
\hline 29 & $\mathrm{~F}$ & Crossbreed & 6 & I/Low \\
\hline 30 & M & Boxer & 8 & I/Low \\
\hline 31 & M & Labrador Retriever & 10 & II/Low \\
\hline 32 & $\mathrm{~F}$ & Crossbreed & 11 & II/Low \\
\hline 33 & M & Crossbreed & 13 & I/Low \\
\hline 34 & $\mathrm{~F}$ & Crossbreed & 15 & III/High \\
\hline
\end{tabular}

F: Female; M: male.

granules, number of nucleoli, and number of mitotic figures. At the same time a two-tier scale (low grade and high grade) according to Kiupel et al. (25) was carried out, based on the morphology of the cell nucleus and the number of mitotic figures.

The main analyses were performed on DNA isolated from tumour tissues and blood samples. DNA was isolated with the use of an automated nucleic acid extraction system QIACube (Qiagen, Hilden, Germany). Isolation of DNA from both whole blood and tumour tissues was obtained in samples from seven dogs (dogs 1-7; Table I). For the remaining $27 \mathrm{dogs}$, it was only possible to isolate DNA from blood only (dogs 8-34; Table I). The DNA samples were assessed quantitatively and qualitatively by electrophoretic separation in $2 \%$ agarose gel and spectrophotometrically by measurements of sample 
Table II. Somatic mutations in cytochrome b $(\mathrm{Cyb})$ gene sequence in blood and tumour tissue in cases of canine mast cell tumour (dogs 1-7).

\begin{tabular}{|c|c|c|c|c|}
\hline $\begin{array}{l}\text { Dog } \\
\text { number }\end{array}$ & $\begin{array}{l}\text { Sequence in } \\
\text { blood }\end{array}$ & $\begin{array}{l}\text { Sequence in } \\
\text { neoplastic } \\
\text { cells }\end{array}$ & $\begin{array}{l}\text { Amino acid } \\
\text { change }\end{array}$ & $\begin{array}{l}\text { Position of } \\
\text { the changed } \\
\text { nucleotide } \\
\text { in the codon }\end{array}$ \\
\hline \multirow[t]{5}{*}{1} & $\mathrm{~m} .14504 \mathrm{C}$ & $\mathrm{m} .14504 \mathrm{G}$ & p.V108L & $\mathrm{GTA} \rightarrow \mathrm{CTA}$ \\
\hline & $\mathrm{m} .14634 \mathrm{C} / \mathrm{T}$ & m.14634C & p.S151F & $\mathrm{TCT} \rightarrow \mathrm{TTT}$ \\
\hline & $\mathrm{m} .14780 \mathrm{C} / \mathrm{T}$ & m.14780C & p.L200L & $\mathrm{CTA} \rightarrow \mathrm{TTA}$ \\
\hline & $\mathrm{m} .15010 \mathrm{C} / \mathrm{T}$ & m.15010C & p.F276F & $\mathrm{TTC} \rightarrow \mathrm{TTT}$ \\
\hline & m.15032A/C & m.15032A & p.I284L & $\mathrm{ATT} \rightarrow \mathrm{CTT}$ \\
\hline \multirow[t]{5}{*}{2} & m.14474G & m.14474A & p.V98M & $\mathrm{GTA} \rightarrow \mathrm{ATA}$ \\
\hline & $\mathrm{m} .14634 \mathrm{C} / \mathrm{T}$ & m.14634C & p.S151F & $\mathrm{TCT} \rightarrow \mathrm{TTT}$ \\
\hline & $\mathrm{m} .14674 \mathrm{C} / \mathrm{T}$ & m.14674C & p.I164I & $\mathrm{ATC} \rightarrow \mathrm{ATT}$ \\
\hline & m.14972A/C & m.14972A & p.T264P & $\mathrm{ACC} \rightarrow \mathrm{CCC}$ \\
\hline & m.14977C & m.14977T & p.P266P & $\mathrm{CCT} \rightarrow \mathrm{CCC}$ \\
\hline \multirow[t]{2}{*}{3} & $\mathrm{~m} .14671 \mathrm{G}$ & m.14671A & p.W163W & $\mathrm{TGG} \rightarrow \mathrm{TGA}$ \\
\hline & m.14930T & m.14930C & p.L250L & $\mathrm{TTA} \rightarrow \mathrm{CTA}$ \\
\hline \multirow[t]{5}{*}{4} & m.14634C & m.14634C/T & p.S151F & $\mathrm{TCT} \rightarrow \mathrm{TTT}$ \\
\hline & m.14674C & $\mathrm{m} .14674 \mathrm{C} / \mathrm{T}$ & p.I164I & $\mathrm{ATC} \rightarrow \mathrm{ATT}$ \\
\hline & m.14780C & $\mathrm{m} .14780 \mathrm{C} / \mathrm{T}$ & p.L200L & $\mathrm{CTA} \rightarrow \mathrm{TTA}$ \\
\hline & m.14977C & $\mathrm{m} .14977 \mathrm{~T}$ & p.P266P & $\mathrm{CCT} \rightarrow \mathrm{CCC}$ \\
\hline & m.15010C & $\mathrm{m} .15010 \mathrm{C} / \mathrm{T}$ & p.F276F & $\mathrm{TTC} \rightarrow \mathrm{TTT}$ \\
\hline \multirow[t]{2}{*}{5} & $\mathrm{~m} .14674 \mathrm{C} / \mathrm{T}$ & m.14674C & p.I164I & $\mathrm{ATC} \rightarrow \mathrm{ATT}$ \\
\hline & $\mathrm{m} .14780 \mathrm{C}$ & $\mathrm{m} .14780 \mathrm{C} / \mathrm{T}$ & p.L200L & $\mathrm{CTA} \rightarrow \mathrm{TTA}$ \\
\hline \multirow[t]{2}{*}{6} & m.14780C & $\mathrm{m} .14780 \mathrm{C} / \mathrm{T}$ & p.L200L & $\mathrm{CTA} \rightarrow \mathrm{TTA}$ \\
\hline & m.15032A & m.15032A/C & p.I284L & $\mathrm{ATT} \rightarrow \mathrm{CTT}$ \\
\hline \multirow[t]{4}{*}{7} & m.T14527T/C & $\mathrm{m} .14527 \mathrm{~T}$ & p.I115I & $\mathrm{ATT} \rightarrow \mathrm{ACC}$ \\
\hline & m.14634C & $\mathrm{m} .14634 \mathrm{C} / \mathrm{T}$ & p.S151F & $\mathrm{TCT} \rightarrow \mathrm{TTT}$ \\
\hline & m.14674C & m.14674C/T & p.I164I & $\mathrm{ATC} \rightarrow \mathrm{ATT}$ \\
\hline & m.14780C & $\mathrm{m} .14780 \mathrm{C} / \mathrm{T}$ & p.L200L & $\mathrm{CTA} \rightarrow \mathrm{TTA}$ \\
\hline
\end{tabular}

absorbance in a Bio Photometer (Eppendorf, Hamburg, Germany). Amplification of the $C y b$ gene (724-base pair fragment) was performed using a polymerase chain reaction (PCR) technique in a T100 Thermal Cycler (Bio-Rad, Wroclaw, Poland). Primer sequences used in the analysis, encompassing a mtDNA fragment $(C y b \mathrm{~F}: 5$, GCACGCAAATGGCGCTTCCA, $C y b$ R: 5'GCATTGGCTAAGGG GCCGGA), were based on already published data (23). The annealing temperature for all the analysed gene fragments was $58.5^{\circ} \mathrm{C}$. Amplicons were sequenced using a Big Dye Terminator Cycle Sequencing kit (Applied Biosystems, Foster City, CA, USA) in Gene Amp PCR system 9700 (Applied Biosystems). The samples were subsequently purified on Centri Sep columns according to the manufacturer's protocol or precipitated with ethanol and sodium acetate according to the protocol provided by the Big Dye kit manufacturer. Extension products were separated on an ABI 377 automated sequencer (Applied Biosystems). Nucleotide sequences were analysed using bioinformatics programs to determine the presence or absence of point mutations and polymorphisms at the analysed loci in tissues (DNA Baser Sequence Assembler v 3.2). The $C y b$ nucleotide sequences were compared with the reference sequence (Gen Bank: U96639) $(26,27)$

All conducted procedures in the study group were approved by the II Local Ethical Commission for Animal Experiments in Lublin, Poland (Resolution number 80/2014). The samples collected for the study did not required dog owners' consent.

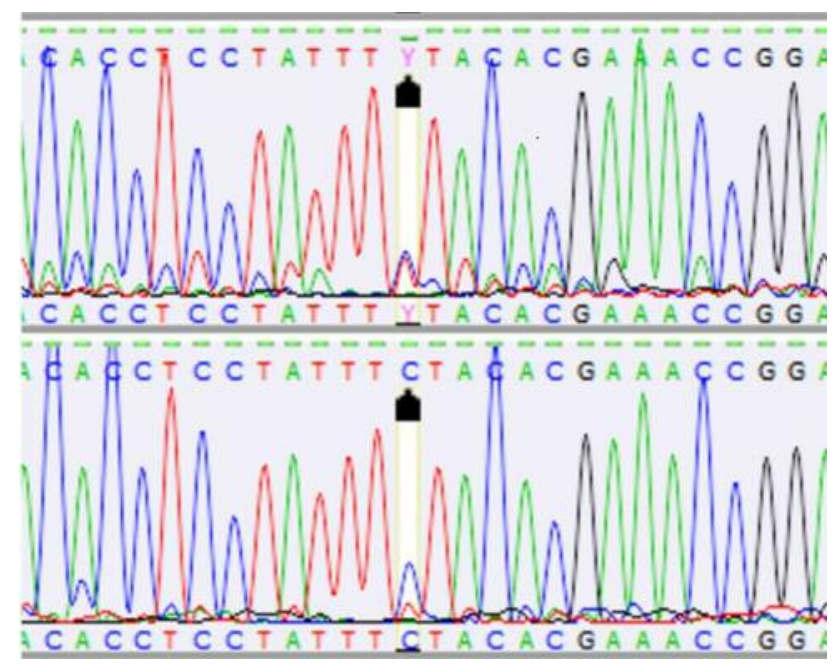

Figure 1. Tumour heteroplasmy (m.14780C/T, upper panel) and blood (lower panel) sequence for mitochondrial cytochrome $b(C y b)$ in position m.14780 in canine mast cell tumour (dog number 4).

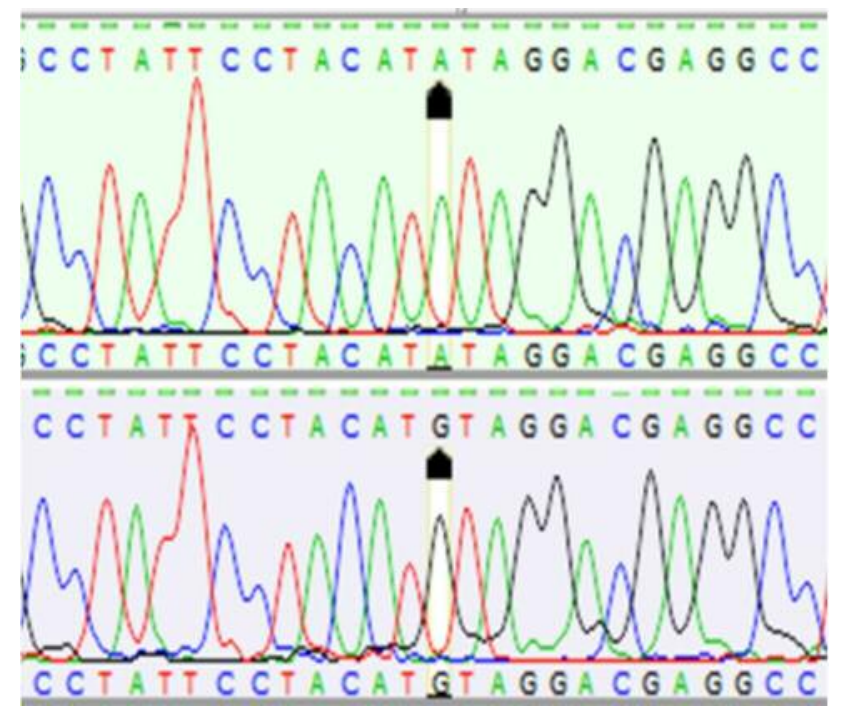

Figure 2. Tumour (upper) and blood (lower) mutation $(G>A)$ of mitochondrial cytochrome $b(C y b)$ in position $m .14474$ in a canine mast cell tumour (dog number 2).

\section{Results}

Somatic mutations or polymorphisms in the $C y b$ gene were detected in all the dogs with MCTs. The analysis revealed a relatively high level of molecular genetic variation between the $C y b$ gene sequence in the tumour tissue and blood of individual animals (dogs 1-7) (Table II). There were mutations in 12 nucleotide positions of the $C y b$ gene in the 
in vivo $33: 57-63(2019)$

Table III. Polymorphisms in the mitochondrial cytochrome b (Cyb) gene in blood in cases of canine mast cell tumour (dogs 1-34).

\begin{tabular}{|c|c|c|c|c|}
\hline Dog number & Reference sequence & Sequences in blood & Amino acid change & $\begin{array}{l}\text { Position of the changed } \\
\text { nucleotide in the codon }\end{array}$ \\
\hline $16,21,26$ & m.14474G & $\mathrm{m} .14474 \mathrm{~A}^{\mathrm{a}}$ & p.V98M & $\mathrm{GTA} \rightarrow \mathrm{ATA}$ \\
\hline $17,19,22$ & $\mathrm{~m} .14527 \mathrm{~T}$ & $\mathrm{~m} .14527 \mathrm{~T} / \mathrm{C}$ & p.I115I & $\mathrm{ATT} \rightarrow \mathrm{ACC}$ \\
\hline 9 & m.14608A & m.14608G & p.G142G & $\mathrm{GGA} \rightarrow \mathrm{GGG}$ \\
\hline $8-11,13-15,19,20,22-25,28-34$ & $\mathrm{~m} .14634 \mathrm{C}$ & $\mathrm{m} .14634 \mathrm{C} / \mathrm{T}^{\mathrm{c}}$ & p.S151F & $\mathrm{TCT} \rightarrow \mathrm{TTT}$ \\
\hline 9 & m.14647T & m.14647C & p.T155T & $\mathrm{TAT} \rightarrow \mathrm{TAC}$ \\
\hline $12,15,23,27,34$ & $\mathrm{~m} .14671 \mathrm{G}$ & $\mathrm{m} .14671 \mathrm{~A}$ & p.W163W & $\mathrm{TGG} \rightarrow \mathrm{TGA}$ \\
\hline $1,6,8,9,11,13-15,18,20,21,23-26,28-34$ & $\mathrm{~m} .14674 \mathrm{C}$ & $\mathrm{m} \cdot 14674 \mathrm{C} / \mathrm{T}^{\mathrm{c}}$ & p.I164I & $\mathrm{ATC} \rightarrow \mathrm{ATT}$ \\
\hline 9 & m.14692G & m.14692A & p.V170V & GTG $\rightarrow$ GTA \\
\hline $2,8,9,11,13-15,19-21,23-25,29,30,32-34$ & $\mathrm{~m} .14780 \mathrm{C}$ & $\mathrm{m} .14780 \mathrm{C} / \mathrm{T}$ & p.L200L & $\mathrm{CTA} \rightarrow \mathrm{TTA}$ \\
\hline $12,15,23,27,34$ & m.14930T & m.14930C & p.L250L & $\mathrm{TTA} \rightarrow \mathrm{CTA}$ \\
\hline 31,33 & m.14972A & m. $14972 \mathrm{~A} / \mathrm{C}^{\mathrm{b}}$ & p.T264P & $\mathrm{ACC} \rightarrow \mathrm{CCC}$ \\
\hline $7,10,11,13,18,22,25,29-31,33$ & $\mathrm{~m} .14977 \mathrm{~T}$ & $\mathrm{~m} .14977 \mathrm{C}^{\mathrm{c}}$ & p.P266P & $\mathrm{CCT} \rightarrow \mathrm{CCC}$ \\
\hline $9,25,28,32$ & m.15010C & $\mathrm{m} .15010 \mathrm{C} / \mathrm{T}^{\mathrm{ac}}$ & p.F276F & $\mathrm{TTC} \rightarrow \mathrm{TTT}$ \\
\hline $25,31-33$ & m.15032A & $\mathrm{m} .15032 \mathrm{~A} / \mathrm{C}^{\mathrm{c}}$ & p.I284L & $\mathrm{ATT} \rightarrow \mathrm{CTT}$ \\
\hline
\end{tabular}

aDetected in female dogs; bdetected in male dogs; cdetected in low-grade mast cell tumours.

blood/tumour tissue of the examined animals (Table II). All the changes were substitution mutations. A majority of the mutations identified were heteroplasmic. Heteroplasmic mutations were detected in seven out of the 12 nucleotide positions (m.14527T/C, m.14634C/T, m.14674C/T, m.14780C/T (Figure 1), m.14972A/C, m.15010C/T, $\mathrm{m} .15032 \mathrm{~A} / \mathrm{C}$ ) in six out of seven of the individuals. In five out of seven of the individuals, heteroplasmy was found in at least one $C y b$ gene nucleotide position both in the tumour tissue and in blood (Table II). Blood and tumour heteroplasmy was recorded in five nucleotide positions of the $C y b$ gene $(\mathrm{m} .14634 \mathrm{C} / \mathrm{T}, \mathrm{m} .14674 \mathrm{C} / \mathrm{T}, \mathrm{m} .14780 \mathrm{C} / \mathrm{T}$, m.15010C/T, m.15032A/C), whereas tumour heteroplasmy was detected in positions m.14527T/C and m.14972A/C. Homoplasmic mutations in mtDNA were detected in five out of the 12 positions in the analysed fragment (m.G14474A (Figure 2), m.G14504C, m.G14671A, m.T14930C, m.T14977C) (Table II). Mutations in mtDNA positions $\mathrm{m} .14780$, m.14634, and m.14674 exhibited the highest frequency (five, four, and four out of the seven dogs, respectively) (Table II). There was an inverse correlation between the number of mutations and tumour grade in the classification according to Kiupel et al. (15). In high-grade MCTs, there were two mutations and only one of the six substitutions was non-synonymous (Table II). In the case of low-grade MCTs, there were from four to five mutations, with one to three non-synonymous substitutions (Table II). The age of the dogs was not correlated with the number of mutations (Table II). Five out of the 12 mutations detected in the canine MCTs resulted in a change in amino acid (Table II). The heteroplasmic $C y b$ gene mutation m.C $14634 \mathrm{C} / \mathrm{T}$ caused a serine-to-phenylalanine substitution
(p.S151F) in four dogs. Mutation m.A15032A/C resulted in a substitution of isoleucine by leucine (p.I284L) in two dogs. Another three non-synonymous mutations were found in single individuals. The heteroplasmic mutation $(A \rightarrow A / C)$ detected in nucleotide position m.14972 in tumour induced a threonine-to-proline substitution (p.T264P). A guanine-toalanine substitution was noted in position m.14474 of mtDNA in blood; it resulted in a substitution of valine by methionine (p.V98M). Similarly, a blood non-synonymous mutation $(\mathrm{G} \rightarrow \mathrm{C})$ in position m.14504 of mtDNA led to a substitution of valine by leucine (p.V108L) in the polypeptide chain. Five out of seven of the examined dogs exhibited from one to three non-synonymous mutations. The presence of only synonymous mutations was detected in two individuals (Table II).

Polymorphisms in the blood of dogs with MCTs, in comparison with the canine reference sequence, were detected in $14 C y b$ gene positions in $31 / 34(91 \%)$ of the examined dogs (Table III). Four of them (m.G14474A, m.C14634T, m.A14972C, m.A15032C) induced amino acid substitutions in the protein (p.V98M, p.S151F, p.T264P, and p.I284L, respectively) (Table III). The highest frequency, i.e. in $20 / 34(59 \%)$ of the dogs, was noted for polymorphisms m.C14634C/T and m.C14674C/T. In 33/34 (97\%) of the dogs with MCTs, there were from one to seven polymorphisms in the $C y b$ gene (Table III). In the case of polymorphisms, heteroplasmy was detected in one to four nucleotide positions of the Cyb gene in $31 / 34$ (91\%) of the dogs (Table III).

Sex-specific polymorphisms were also observed. Polymorphism in position m.14474 was detected in three females (no. 16, 21, 26) and in five females (no. 1, 9, 25, 28, 32 ) in position m.15010. In turn, polymorphism in m.14972 
was found only in three male dogs $(2,31,33)$ (Table III). Tumour grade-specific polymorphisms according to the classification proposed by Kiupel et al. (15) were also noted. Substitutions in positions $\mathrm{m} .15010$ and $\mathrm{m} .15032$ were found in low-grade MCTs, but were not detected in high-grade tumours (Tables I and III). The polymorphisms in positions $\mathrm{m} .14634, \mathrm{~m} .14674$, and $\mathrm{m} .14977$ were more frequent in the case of low-grade than in the high-grade tumours. The number of polymorphisms ranged from 1 to 7 in low-grade MCTs and from 0 to 5 in high-grade tumours. In our study, we did not observe any relationship between the age and breed of the dogs with polymorphisms. The mean number of polymorphisms per individual was higher in the group with low-grade tumours (median=3.5) than in the high-grade MCTs (median=3.0).

\section{Discussion}

Previous investigations on the aetiology of MCTs associated them with changes in nDNA. The only published report of the mitochondrial genomics of MCTs was focused on the Dloop, which controls replication and transcription of mtDNA. Somatic mutations in seven positions of the D-loop nucleotide sequences were detected in $47 \%$ of dogs with MCTs, while polymorphisms were identified in $94 \%$ of the dogs (19). The previous and present research confirmed the relatively high molecular genetic variation in the mitochondrial genome in MCTs, which may be related to tumorigenesis. The mutations were detected in both low-and high-grade tumours. However, an inverse correlation was noted between the number of mutations and the tumour grade according to Kiupel et al.'s classification (25) (Table II). The $c$-Kit nDNA mutation in exon 11 described so far in MCTs was associated only with tumours with a higher malignancy grade and worse prognosis; it was not observed in tumours with a more benign character $(3,4)$. In turn, in the case of the $C y b$ gene, a greater number of mutations were found in low-grade tumours. These mutations probably appear in the initial stage of cancer and might even initiate the carcinogenic process. This is supported by the occurrence of such mtDNA mutations in the human population also in dysplastic changes regarded as pre-cancerous states $(7,8)$. Mutations of genes in mtDNA encoding respiratory chain proteins, including cytochrome $b$, induce disturbances in electron transport and promote generation of reactive oxygen species. It should be noted that the later leads to the initiation and development of cancer and damage to the nuclear genome $(7,8)$. Whether there are correlations between mutations in the nuclear and mitochondrial genomes should be elucidated by further studies focused on both genomes.

Most changes within the mtDNA nucleotide sequences of neoplastic cells are of homoplasmic nature, i.e. all DNA molecules in the cell are the same $(6,8)$. This was not confirmed in our studies, however, since the majority of the mutations were heteroplasmic (Table II). This may be associated with the initial stage of carcinogenesis. At the beginning of the neoplastic process, cells may contain mutant and wild-type mtDNA copies. Only subsequent divisions of mutant cells can lead to homoplasmy. The presence of mutations in the $C y b$ gene in low-grade tumours may also indicate an early stage of carcinogenesis. However, this needs further study. In earlier reports on mitochondrial genomics in canine tumours, the phenomenon of heteroplasmy was detected in single cases (14-18). One report of a mitochondrial defect in the $C y b$ gene in canine tumours described heteroplasmic mutations in sebaceous gland epithelioma and centroblastic lymphoma. The mutation in the tumour tissue was found in position A587A/C. It was also found in position $738 \mathrm{~A} / \mathrm{C}$ in the lymphoma (16). In a previous study of the D-loop in MCTs, heteroplasmy was detected in two cases. In one individual, heteroplasmy was present in the blood and tumours in position m.C15815C/T; in another dog, heteroplasmic changes were found only in tumour tissue in positions m.C15912T/C and m.C16025T/C (19). Coller et al. (28) suggest that homoplasmy is the result of random segregation of mitochondria during division. During consecutive divisions, heteroplasmy may persist or homoplasmy may occur through genetic drift (7), which results in elimination of rare variants of mtDNA. The mutual proportions of mutant and wild-type mtDNA can vary during division, leading to changes in the cellular phenotype. Phenotypic expression has clinical importance and exerts an impact on the manifestation of disease symptoms (29). MCTs are characterised by a varied clinical course. They take the form of small, demarcated, single or multiple tumours and infiltrate surrounding tissues (30). Can the clinical picture be associated with the phenomenon of heteroplasmy? It is difficult to provide an answer to this question at this stage of the research; however, the high frequency of this phenomenon in the $C y b$ gene in MCTs, compared with other tumour types, is puzzling (16). Five out of seven individuals exhibited heteroplasmy in both their tumour tissue and blood (Table II). In the case of malignant tumours such as MCT, the presence of mutations in blood may be related to the transport of tumour cells with the mutant variant of the gene into the bloodstream through tumour blood vessels (7). The occurrence of mutations in blood can be the basis for further investigations focused on identification of prognostic markers and tumour progression.

Due to their influence on the structure of proteins of the oxidative phosphorylation chain, polymorphisms alter the course of cell processes and modify cell susceptibility to neoplastic transformation $(6,11)$. So far, intensive research on the role of polymorphisms in oncogenesis has been carried out on breast cancer in women $(9-12,31,32)$. Correlations have been found between polymorphism in 
m.G10398A and m.T10400C of mitochondrial NADHdehydrogenase subunit $3(M T-N D 3)$ and a high risk of breast cancer development $(11,32)$. Investigation conducted by Igman et al. (31), helped to establish the patterns of 63 polymorphisms present in patients with breast cancer. In turn, Grzybowska-Szatkowska et al. (9) detected the greatest number of polymorphisms in the sequence of the mitochondrially encoded NADH: ubiquinone oxidoreductase core subunit 2 gene (MT-ND2).

It has been found that polymorphisms can affect the function of mitochondria, especially if they lie on conservative domains of the mitochondrial proteins. These changes can promote the selective prevalence of mutant mtDNA over the wild-type mtDNA, which may be involved in the process of carcinogenesis (10). The negative effect of polymorphisms on protein function has been confirmed in malignant canine tumours $(16,18)$. Ślaska et al. have shown harmful effects of changes in polypeptides in four positions: T193N, V98M, V118M, and H196P on the structure and function of proteins (14). This promotes disorders in electron transport and the energy level in cells.

In this study, polymorphisms in blood were detected in all individuals (Table III). The highest frequency of polymorphisms was found in two positions: m. C14634C/T and m.C14674C/T, which may predispose to the development of MCT.

As in the case of mutations, the high frequency of heteroplasmy, which was noted in as many as $91 \%$ (31/34) of the dogs in one to four $C y b$ gene nucleotide positions, is surprising (Table III). In the initial stage of carcinogenesis, cells contain mutant and wild-type mtDNA copies. The use of polymorphisms as tumour markers could be a very useful tool in the diagnostics of MCTs. To our knowledge for the first time, sex-specific polymorphisms were detected. The polymorphisms in positions $\mathrm{m} .14474$ and $\mathrm{m} .15010$ were only found in females, whereas the polymorphism in m.14972 was present only in males (Table III). Literature data demonstrate no relationship between MCT development and the animal's sex $(1,2)$. Molecular analysis here revealed sex-specific polymorphisms that may be associated with the risk of MCT development in females and males. However, further investigations with a greater number of individuals are required. Furthermore, the polymorphisms in position $\mathrm{m} .15010 \mathrm{C} / \mathrm{T} \mathrm{m} .15032 \mathrm{~A}$ were detected only in low-grade MCTs (Table III). Could the presented polymorphisms be prognostic markers? The answer to this question requires further research considering the course of the tumour disease and survival rates. To date, a correlation of polymorphisms in position $\mathrm{m} .8242 \mathrm{C} / \mathrm{T}$ of the ATP synthase F0 subunit 6 gene (Atp6) and m.7383T/C of the cytochrome $c$ oxidase subunit II gene $(\operatorname{Cox} 2)$ with a large body size and older age has been noted only in female dogs with mammary tumours. In our previous and available studies on mitochondrial genomics in dogs, there was no relation between polymorphism and breed susceptibility (14-19). However, interesting results of molecular analyses of nuclear genes were obtained in Golden Retriever dogs: polymorphisms in the G protein subunit alpha i2 gene (Gnai2) and hyaluronidase genes have been associated with the risk of MCT development (33).

\section{Conclusion}

The present investigations demonstrated high molecular genetic variation in the cytochrome $b$-encoding gene in MCTs. There are many scientific theories regarding cancer transformation. One of them assumes that mutations are a result of tumour diseases $(6,10)$. However, the vast majority of researchers support the view that mutations and polymorphisms promote tumour development. This hypothesis seems to be confirmed in the present study. The presence of numerous mutations and polymorphisms in blood and tumour tissues and the high frequency of heteroplasmy indicate their involvement in the process of neoplastic transformation. It cannot be excluded that these mutations and polymorphisms are directly associated with the development of mast cell tumours in dogs and may be used for diagnosis of tumours. As the results come from a limited number of cases, further studies on the significance of mutations and their association with neoplastic transformation as well as the biological behaviour of canine MCTs are required.

\section{Conflicts of Interest}

The Authors declare that they have no competing interests in regard to this study.

\section{References}

1 Welle MM, Bley CR, Howard J, Rüfenacht S: Canine mast cell tumours: a review of the pathogenesis, clinical features, pathology and treatment. Vet Dermatol 19: 321-339, 2008.

2 Blackwood L, Murphy S, Buracco P, De Vos JP, De FornelThibaud P, Hirschberger J, Kessler M, Pastor J, Savary-Bataille $\mathrm{K}$ and Argyle DJ: European consensus document on mast cell tumours in dogs and cats. Vet Comp Oncol 10: e1-e29, 2012

3 Zemke D, Yamini B and Yuzbasiyan-Gurkan V: Mutations in the juxta membrane domain of c-KIT are associated with higher grade mast cell tumors in dogs. Vet Pathol 39: 529-535, 2002.

4 Webster JD, Yuzbasiyan-Gurkan V, Miller RA, Kaneene JB and Kiupel M: Cellular proliferation in canine cutaneous mast cell tumors: associations with c-KIT and its role in prognostication. Vet Pathol 44: 298-308, 2007.

5 Letard S, Yang Y, Hanssens K, Palmérini F, Leventhal PS, Guéry S, Moussy A, Kinet JP, Hermine O and Dubreuil P: Gain-offunction mutations in the extracellular domain of KIT are common in canine mast cell tumors. Mol. Cancer Res 6: 1137-1145, 2008.

6 Czarnecka AM, Golik P and Bartnik E: Mitochondrial DNA mutations in human neoplasia. J Appl Genet 47: 67-78, 2006.

7 Grzybowska-Szatkowska L and Ślaska B: Mitochondrial DNA and carcinogenesis (Review). Mol Med Rep 6: 923-930, 2012. 
8 Ślaska B, Grzybowska-Szatkowska L, Bugno-Poniewierska M, Surdyka $M$ and Śmiech A: Nuclear and mitochondrial DNA mutation in human and canine tumors. Med Weter 69: 195-202, 2013

9 Grzybowska-Szatkowska L and Ślaska B: Mitochondrial NADH-dehydrogenase polymorphisms are associated with breast cancer in Poland. J Appl Genet 55: 173-181, 2014.

10 Grzybowska-Szatkowska L, Slaska B, Rzymowska J, Brzozowska A and Floriańczyk B: Novel mitochondrial mutations in the ATP6 and ATP8 genes in patients with breast cancer. Mol Med Rep 4: 1772-1778, 2014.

11 Czarnecka AM, Krawczyk T, Zdrozny M, Lubiński J, Arnold RS, Kukwa W, Scińska A, Golik P, Bartnik E and Petros JA: Mitochondrial NADH-dehydrogenase subunit 3 (ND3) polymorphism (A10398G) and sporadic breast cancer in Poland. Breast Cancer Res Treat 121: 511-518, 2010.

12 Parrella P, Yan Xiao Y, Fliss M, Sanchez-Cespedes M, Mazzarelli P, Rinaldi M, Nicol T, Gabrielson E, Cuomo C, Cohen C, Pandit S, Spencer M, Rabitti C, Fazio VM and Sidransky D: Detection of mitochondrial DNA mutations in primary breast cancer and fine-needle aspirates. Cancer Res 61: 7623-7626, 2001.

13 Cai FF, Kohler C, Zhang B, Chen WJ, Barekati Z, Garritsen HS, Lenner P, Toniolo P, Zhang JJ and Zhong XY: Mutation of mitochondrial DNA as potential biomarkers in breast cancer. Anticancer Res 31: 4267-4272, 2011.

14 Ślaska B, Grzybowska-Szatkowska L, Surdyka M, Nisztuk S, Rozanska D, Rozanski P, Smiech A and Orzelski M: Mitochondrial D-loop mutations and polymorphisms are connected with canine malignant cancers. Mitochondr DNA 25 : 238-243, 2014.

15 Ślaska B, Surdyka M, Brodzki A, Nisztuk S, Gurgul A, BugnoPoniewierska M, Śmiech A, Różńska D and Orzelski M: Mitochondrial D-loop mutations can be detected in sporadic malignant tumours in dogs. Bull Vet Inst Pulawy 58: 631-637, 2014.

16 Ślaska B, Grzybowska-Szatkowska L, Nisztuk S, Surdyka M and Rozanska D: Mitochondrial DNA polymorphism in genes encoding ND1, COI and CYTB in canine malignant cancers. Mitochondr DNA 26: 452-458, 2015.

17 Surdyka M and Ślaska B: Defect of the mitochondrial DNA hypervariable region as a risk factor for canine mammary tumour. Vet. Comp Oncol 15: 820-828, 2017.

18 Surdyka M and Ślaska B: Defect in Nd2, Cox2, Atp6, and Cox3 mitochondrial genes as a risk factor for canine mammary tumour. Vet Comp Oncol 15: 1062-1072, 2017.

19 Śmiech A, Ślaska B, Surdyka M, Grzybowska-Szatkowska L, Łopuszyński W and Różańska D: Identification of additional mitochondrial DNA mutations in canine mast cell tumours. Acta Vet Scand 58: 28, 2016.

20 Xia D, Yu CA, Kim H, Xia JZ, Kachurin AM, Zhang L, Yu L and Deisenhofer J: Crystal structure of the cytochrome BC1 complex from bovine heart mitochondria. Science 277: 60-66, 1997.

21 Voo KS, Zeng G, Mu JB, Zhou J, Su, XZ and Wang RF: CD4+ $\mathrm{T}$-cell response to mitochondrial cytochrome $\mathrm{b}$ in human melanoma. Cancer Res 66: 5919-5926, 2006.

22 Dasgupta S, Hoque MO, Upadhyay S and Sidransky D: Mitochondrial cytochrome $\mathrm{b}$ gene mutation promotes tumor growth in bladder cancer. Cancer Res 3: 700-706, 2008.
23 Hendrick MJ, Mahaffey EA, Moore JH and Walder EJ: Histological Classification of Mesenchymal Tumors of Skin and Soft Tissues of Domestic Animals. In: WHO International Histological Classification of Tumors of Domestic Animals. Second Series. Volume 2. Armed Forces Institute of Pathology, Washington, D.C., pp. 28-29, 1998.

24 Patnaik AK, Ehler WJ and Macewen EG: Canine cutaneous mast cell tumour: morphologic grading and survival time in $83 \mathrm{dogs}$. Vet Pathol 21: 469-474, 1984.

25 Kiupel M, Webster JD, Bailey KL, Best S, Delay J, Detrisac CJ, Fitzgerald SD, Gamble D, Ginn PE, Goldschmidt MH, Hendrick MJ, Howerth EW, Janovitz EB, Langohr I, Lenz SD, Lipscomb TP, Miller MA, Misdorp W, Moroff S, Mullaney TP, Neyens I, O'Tolle D, Ramos-Vara J, Scase TJ, Schulman FY, Sledge D, Smedley RC, Smith K, Snyder P, Southorn E, Stedman NL, Steficek BA, Stromberg PC, Valli VE, Weisbrode SE, Yager J, Heller J and Miller R: Proposal of a 2-tier histologic grading system for canine cutaneous mast cell tumors to more accurately predict biological behavior. Vet Pathol 48: 147-155, 2011.

26 DNA Baser Sequence Assembler 3.2. HeracleBioSoft SRL Romania. http://www.DnaBaser.com, 2012.

$27 \mathrm{Kim} \mathrm{KS}$, Lee SE, Jeong HW and Ha JH: The complete nucleotide sequence of the domestic dog (Canis familiaris) mitochondrial genome. Mol Phylogenet Evol 10: 210-220, 1998.

28 Coller HA, Khrapko K, Bodyak ND, Nekhaeva E, HerreroJimenez P and Thilly WG: High frequency of homoplasmic mitochondrial DNA mutations in human tumours can be explained without selection. Nat Genet 28: 147-150, 2001.

29 Filosto $M$ and Mancuso $M$ : Mitochondrial diseases: Anosological update. Acta Neurol Scand 115: 211-221, 2007.

30 Śmiech A, Ślaska B and Łopuszyński W: Epidemiological study of canine mast cell tumours according to the histological malignancy grade. Pol J Vet Sci 20: 455-465, 2017.

31 Ingman $M$ and Gyllensten U: mtDB: Human Mitochondrial Genome Database, a resource for population genetics and medical sciences. Nucleic Acids Res 34(Database issue): D749$751,2006$.

32 Mims MP, Hayes TG, Zheng S, Leal SM, Frolov A, Ittmann MM, Wheeler TM and Prchal JT: Mitochondrial DNA G10398A polymorphism and invasive breast cancer in African-American women. Cancer Res 66: 1880-1881, 2006.

33 Arendt ML, Melin M, Tonomura N, Koltookian M, CourtayCahen C, Flindall N, Bass J, Boerkamp K, Megquir K, Youell L, Murphy S, McCarthy C, London Ch, Rutteman GR, Starkey $M$ and Linbald-Toh K: Genome-wide association study of golden retrievers identifies germ-line risk factors predisposing to mast cell tumours. PLoS Genet 11: e1005647, 2015.

Received September 5, 2018 Revised October 8, 2018 Accepted October 12, 2018 